\title{
Improvement of Oxidative Stability and Microbial Shelf Life of Vanilla Cake by Coconut Oil Meal and Sesame Oil Meal Phenolic Extracts
}

\author{
Chathuri M. Senanayake, C. Harshani Algama, Ruwani L. Wimalasekara, \\ W. N. M. T. D. N. Weerakoon, Nimanthi Jayathilaka $\mathbb{D}$, and Kapila N. Seneviratne $\mathbb{C}$ \\ Department of Chemistry, Faculty of Science, University of Kelaniya, Kelaniya, Sri Lanka \\ Correspondence should be addressed to Nimanthi Jayathilaka; njayathi@kln.ac.lk and Kapila N. Seneviratne; kapilas@kln.ac.lk
}

Received 12 June 2019; Revised 7 October 2019; Accepted 6 November 2019; Published 22 November 2019

Academic Editor: Efstathios Giaouris

Copyright (C) 2019 Chathuri M. Senanayake et al. This is an open access article distributed under the Creative Commons Attribution License, which permits unrestricted use, distribution, and reproduction in any medium, provided the original work is properly cited.

\begin{abstract}
Phenolic extracts of coconut oil meal (CME) and sesame oil meal (SME) were compared with synthetic antioxidants for the potential of improving shelf life of vanilla cake. CME maintained hexanal (product of chemical spoilage) levels below $0.3 \mathrm{mg} / \mathrm{kg}$ in cake up to 14 days. BHT- and SME-added cakes maintained hexanal levels below $2 \mathrm{mg} / \mathrm{kg}$, while control cake with no added antioxidants exceeded this level by day 14. Both CME and SME extended the microbial shelf life up to 13 days, while control and BHT-added cake exceeded the maximum allowed colony count by day 7 and day 11, respectively. The results indicate that the onset of microbial spoilage of vanilla cake is faster than the chemical spoilage, and addition of CME and SME extends both microbiological and chemical stability of cakes beyond day 7 during storage. Over $90 \%$ of the antioxidant activity of CME and SME retained after heating at $180^{\circ} \mathrm{C}$ for $2 \mathrm{~h}$. CME and SME are ideal thermally stable natural alternatives for synthetic antioxidants in vanilla cake.
\end{abstract}

\section{Introduction}

Antioxidants can stabilize food by retarding the oxidation of fat or oils present in foods. Due to the health concerns associated with the synthetic antioxidants, there is high interest in the use of natural antioxidants as food preservatives. Natural antioxidants consist of vitamins, tocopherols, carotenoids, and phenolic compounds capable of preserving food. For instance, the amount of Echinacea purpurea extracts needed to achieve the lowest peroxide value in cakes was $1000 \mathrm{mg} / \mathrm{kg}$, and the amount of the same extracts to achieve highest antimicrobial activity in cake was $1500 \mathrm{mg} / \mathrm{kg}$ [1]. However, poor thermal stabilities of some natural antioxidants limit their use in food preservation. Processing pineapple into jam destroyed nearly $50 \%$ of the vitamin C content [2]. Some Malaysian herbal aqueous extracts improved the oxidative stability of cake compared with the control cake with no added antioxidants. However, the synthetic antioxidants, butylated hydroxyanisole (BHA) and butylated hydroxytoluene (BHT), provided higher oxidative stability to cake [3]. Though natural antioxidants such as vitamin $\mathrm{E}$ can be used to improve the shelf life of bakery products, considerable amount of vitamin $\mathrm{E}$ is lost during baking [4]. The vitamin E content in milled barley decreased by $8 \%$ at $120^{\circ} \mathrm{C}$ within $24 \mathrm{~h} \mathrm{[5].} \mathrm{Therefore,} \mathrm{thermal}$ stability is an important factor in deciding the effectiveness of the antioxidants in bakery products. In addition, when using natural antioxidants for improving the shelf life of cakes, it is also important to consider the impact of added antioxidants on sensory quality. Certain plant extracts add off-flavors to food products and are not suitable as preservatives. Extracts from plants such as garcinia, curcumin, vanillin, and mint have been shown to have limited uses in bakery products [6].

Natural phenolic antioxidants such as phenolic acids and flavonoids are more stable than vitamin antioxidants in food 
systems during high-temperature processing and storage [7]. Both coconut and sesame oil are rich in phenolic antioxidants that mainly originate from the kernel. Agricultural byproducts have been well utilized for the extraction of useful polysaccharides with antioxidant and antimicrobial activities [8]. The residues remaining after expulsion of oil from coconut and sesame kernels are called coconut oil meal and sesame oil meal, respectively. These oil meals are byproducts of Asian food industries. Studies have shown that sesame oil meal extracts are more effective in stabilizing sunflower and soybean oil than BHT and BHA [9]. Heat stability of sunflower oil has been shown to improve by incorporating olive waste cake extracts at $200 \mathrm{mg} / \mathrm{kg}$ [10].

In addition to improving antioxidant properties, natural phenolic substances improve antimicrobial properties in foods [11]. Oxidative stability and microbial shelf life are the two important factors that determine the overall shelf life of bakery products. Based on the above literature, we hypothesized that CME and SME contain high amounts of phenolic antioxidants that can improve the shelf life of vanilla cake. Present investigation involves evaluation of the thermal stability and the potential of CME and SME to improve the shelf life of vanilla cake and the impact of application of these extracts on the sensory quality of cake.

\section{Materials and Methods}

2.1. Chemicals. 1,1-diphenyl-2-picrylhydrazyl (DPPH) radical, butylated hydroxytoluene (BHT), butylated hydroxyanisole (BHA), tert-butylhydroquinone (TBHQ), deoxyribose and authentic HPLC standards ( $\geq 99 \%$ ) (apigenin, caffeic acid, catechin, chlorogenic acid, cinnamic acid p-coumaric acid, daidzein, ellagic acid, epigallocatechin, ferulic acid, galangin gallic acid, genistein, kaempferol, luteolin, naringenin, syringic acid and vanillic acid), and GC standard (98\%) (hexanal) were purchased from Sigma (St. Louis, MO). All other chemicals were purchased from either Sigma or Fluka (Buchs, Switzerland).

2.2. Sample Preparation. Coconut oil meal and sesame oil meal were gifts from local mills in Western Province in Sri Lanka. The samples were air-dried at $40^{\circ} \mathrm{C}$ until a constant weight was obtained, ground using a kitchen grinder, sieved through a $180 \mu \mathrm{m}$ mesh, and kept at $-20^{\circ} \mathrm{C}$ until further use.

2.3. Total Phenol Contents and Antioxidant Activities. Ethanol:water $(70: 30 \mathrm{v} / \mathrm{v})$ solvent system $(1.0 \mathrm{~mL})$ was mixed with the powder of the oil meal $(0.2 \mathrm{~g})$, and total phenol contents of the meal extracts were determined using Folin Ciocalteu reagent as described earlier [12]. DPPH radical scavenging assay, ferric reducing antioxidant power (FRAP) assay, and deoxyribose degradation assay were performed as described by Seneviratne and Kotuwegedara [13] at $30 \mu \mathrm{g} / \mathrm{mL}$ concentration of phenolic substances. Antioxidant activity in egg yolk homogenate was determined according to a previously reported method [12].
2.4. Identification of Phenolic Compounds. Purification of the ethanol:water $(70: 30 \mathrm{v} / \mathrm{v})$ extracts of oil meals was performed, and phenolic compounds were identified by a reported HPLC method with minor modifications to elution programme [14]. HPLC experiments were carried out using an Agilent 1260 Infinity liquid chromatographic system (Waldbronn, Germany) equipped with an Agilent 1200 photo diode array (PDA) detector. A ZORBAX ECLIPSE Plus C18 column (Agilent Technologies, USA) $(4.6 \times 100 \mathrm{~mm} \times 3.5 \mu \mathrm{m}$ particle size $)$ maintained at room temperature (RT) was used for this purpose. The mobile phase consisted of $0.001 \mathrm{M}$ sulfuric acid in deionised water (A) and methanol (B). The elution gradient at a flow rate of $0.5 \mathrm{~mL} / \mathrm{min}$ using $95 \% \mathrm{~A} / 5 \% \mathrm{~B}$ was continued for $15 \mathrm{~min}$. From 15 to $30 \mathrm{~min}$, solvent B was increased to $10 \%$. Then, solvent B was increased by $10 \%$ at every $10 \mathrm{~min}$ up to $70 \%$. From $90-110 \mathrm{~min}$, solvent B was increased to $80 \%$. The sample $(20 \mu \mathrm{L})$ was injected into the HPLC system and detected at $280 \mathrm{~nm}$. UV spectra of the eluted compounds were also detected by PDA detection. Galangin was used as the internal standard (ISTD). Phenolic compounds of CME and SME were identified by comparison of the retention times and UV spectra of authentic standards in HPLC as reported [15].

2.5. Rancimat Test of Thermal Stability of Phenolic Extracts Using Sunflower Oil. Phenolic substances naturally present in sunflower oil were removed by passing through a packed column of activated alumina according to a reported method [16]. Solvent was removed from phenolic extracts or synthetic antioxidants under a stream of nitrogen. The dried phenolic extracts were heated in an oven at $180^{\circ} \mathrm{C}$ for $120 \mathrm{~min}$ and cooled to room temperature before dissolving the resultant residue in phenol-stripped sunflower oil (3.2 g) at $100 \mathrm{mg} / \mathrm{kg}$ by vortex mixing $(40 \mathrm{~Hz}, 2 \mathrm{~min})$ to obtain a clear solution. The control was prepared by adding phenolstripped sunflower oil with no added antioxidants. The induction time (IT) of the oils in the tubes was determined at $120^{\circ} \mathrm{C}$ using the Rancimat apparatus (892 Professional Rancimat, Metrohm, Switzerland). The protection factor (PF) was calculated as $\mathrm{PF}=\left(\mathrm{IT}_{\text {(antioxidant-added oil })} / \mathrm{IT}_{(\text {control })}\right)$. The experiment was repeated under the same conditions without heating the phenolic extracts at $180^{\circ} \mathrm{C}$ to calculate the percentage activity retained after heating.

\subsection{Shelf Life of Vanilla Cake}

2.6.1. Preparation of Vanilla Cake. Cake samples were prepared by mixing CME or SME or BHT to give $20 \mathrm{mg} /$ $100 \mathrm{~g}$ of margarine added to the cake according to a reported procedure [15]. Control cake was prepared without adding any antioxidant extract. Cake formula included whole purpose wheat flour (100 g), sugar (85 g), margarine (100 g), baking powder $(2 \mathrm{~g})$, beaten eggs $(25 \mathrm{~g})$, milk $(20 \mathrm{~mL})$, and vanilla $(2 \mathrm{~g})$. Baking conditions were at $160^{\circ} \mathrm{C}$ for $30 \mathrm{~min}$ in a preheated electric oven (TR02000/TR2000R/TR050/TR055/ TR060, Black \& Decker, USA). 
2.6.2. Cake Properties. Moisture content and porosity of the cakes were determined according to reported methods [17]. To determine the porosity, a compaction load of $20 \mathrm{~kg}$ was applied to the cake sample placed in a $2.57 \mathrm{~cm}$ diameter cylindrical container. Initial height and the heights of the cake samples after pressing for 2 minutes were recorded using a Vernier caliper. Assuming all pores in the sample were compressed, porosity was calculated as porosity $(\%)=\left(\left(H_{\mathrm{i}}-\mathrm{H}_{\mathrm{f}}\right) / H_{\mathrm{i}}\right) \times 100$, where $H_{\mathrm{i}}$ was the initial height of the sample and $H_{\mathrm{f}}$ was the final height of the sample.

The cakes were photographed using a digital camera (Nikon Coolpix L120) under the same diffused daily light conditions. The original images $(640 \times 480$ pixels $)$ were formatted in JPEG. Segmentation to differentiate background and analysis of pore area were performed using ImageJ software (Wayne Rasband, OS-windows 10/8/7/ vista/xp). Pixel values were converted to distance units using bars of known length. Pore area was calculated after adjusting and setting the threshold values. The RGB coordinates of the images were transformed into CIE $L^{*} a^{*} b^{*}$ color space for the analysis of color parameters. Mean values for CIE $L^{*} a^{*} b^{*}$ color space per unit area was determined for ten different areas of the cake crumb for four crumb sections imaged from each cake sample.

2.6.3. Microbial Shelf Life of Cake. Standard protocols $[18,19]$ were adopted for the aerobic plate count (APC) and yeast and mold count (YMC) at two-day intervals for 12 days of storage. Each cake sample $(1.0 \mathrm{~g})$ was stored at room temperature under sterile conditions in stomacher bags. The cake samples were homogenized in $9.0 \mathrm{~mL}$ of $0.1 \%$-buffered peptone water (CM1049) and $1.0 \mathrm{~mL}$ of each homogenized serial dilution was transferred to a sterile Petri dish in triplicate. Pour plate technique was performed using Plate Count Agar (CM0325) plates incubated at $37^{\circ} \mathrm{C}$ for 48 hours to determine the APC according to ISO 7218 [20]. $1.0 \mathrm{~mL}$ of each dilution was transferred to the sterile petri dish in triplicate to determine YMC using pour plate technique in sterile Potato Dextrose Agar (M096) plates incubated at $25^{\circ} \mathrm{C}$ for 4 days according to ISO 7218 [20].

2.6.4. Oxidative Stability of Cake. Each cake sample (50 g) was ground well, and hexane $(150 \mathrm{~mL})$ was added and shaken in an orbital shaker for $20 \mathrm{~min}$. The lipid extract was decanted, and the extraction was continued with two fresh portions of hexane. All the extracts were combined, dried over anhydrous sodium sulphate, filtered, and hexane was evaporated in a rotary evaporator. Traces of hexane in the lipid was removed by flushing with nitrogen and stored at $-20^{\circ} \mathrm{C}$ until further analysis.

The peroxide value of the lipid fraction extracted with hexane was determined as reported by Shantha and Decker [21]. Hexanal was measured based on a reported method using a gas chromatograph 2010 plus equipped with an AOC-5000 plus autosampler (Shimadzu, Japan) [22]. Each ground cake sample $(4.0 \mathrm{~g})$ placed in headspace vials capped with aluminium caps with PTFE/silicone septa were shaken and heated at $55^{\circ} \mathrm{C}$ for $13 \mathrm{~min}$ in an autosampler heating block. A $100 \mu \mathrm{m}$ PDMS solid phase microextraction (SPME) fiber needle from Supelco (St. Louis, MO) was injected into the vial for $3 \mathrm{~min}$ to absorb volatiles and was then transferred to the injector port $\left(250^{\circ} \mathrm{C}\right)$ for $1 \mathrm{~min}$. The injection port was operated in the split mode, and the split ratio was $1: 5$. Volatile compounds were passed through a capillary column $\mathrm{Rtx}^{\mathrm{R}}$ - WAX (cross bond with PEG, $30 \mathrm{~m} \times 0.32 \mathrm{~mm}$ i.d. $0.25 \mu \mathrm{m}$ ) at $65^{\circ} \mathrm{C}$ for $10 \mathrm{~min}$. The carrier gas was helium at a flow rate of $2.0 \mathrm{~mL} \cdot \mathrm{min}^{-1}$. Concentrations of hexanal in the samples were determined by a standard curve prepared from authentic hexanal standard using a flame ionization detector at $250^{\circ} \mathrm{C}$.

2.6.5. Sensory Quality of Cake Samples. Sensory quality of the cake samples was evaluated using 30 trained panelists adopting a previously reported procedure [23]. Cake samples (about $3 \times 3 \times 1.5 \mathrm{~cm}$ ) baked within the previous $10 \mathrm{~h}$ were served to each panelist in a randomized order. The panelist's mouth was rinsed with water to remove any traces of residual food. Each panelist was asked to rate the quality attributes according to appearance, color, odor, taste, texture (hardness and softness), and overall acceptability of each sample using a 5 -point hedonic scale $(1=$ dislike very much and $5=$ like very much).

2.7. Statistical Analysis. All samples were analyzed in triplicate unless otherwise indicated. Two sample $t$-tests and ANOVA were carried out for the determination of significant differences $(p<0.05)$ between the means. Data were analyzed using Minitab (version 17 for Windows).

\section{Results and Discussion}

Phenolic contents of coconut meal and sesame meal as determined by Folin Ciocalteu assay are $775 \pm 26 \mathrm{mg}$ gallic acid eqv./kg, $2113 \pm 291 \mathrm{mg}$ gallic acid eqv./kg dried meal, respectively. Antioxidant activities of CME, SME, BHT, $\mathrm{BHA}$, and TBHQ as determined by DPPH radical scavenging activity and ferric reducing power are given in Table 1 . Both DPPH radical scavenging activity and ferric reducing power of CME are significantly higher $(p<0.05)$ than those of SME and BHT. Antioxidant activities of plant extracts prepared under different conditions using various solvents have been compared with those of BHT. The DPPH radical scavenging activity of BHT reported in the present study is comparable with the reported values. DPPH radical scavenging activity of CME and SME is superior to that of some plant extracts prepared and analyzed under conditions similar to the conditions used in the present study [24, 25]. TBHQ has significantly higher DPPH radical scavenging activity compared with CME, SME, and other synthetic antioxidants $(p<0.05)$. Higher DPPH radical scavenging activity of TBHQ compared with SME has been reported [9]. However, ferric reducing power of TBHQ is not significantly different from that of SME. Deoxyribose degradation by hydroxyl radicals can be inhibited by phenolic compounds [26]. Both CME and SME display significantly higher $(p<0.05)$ inhibition of deoxyribose degradation compared 
TABLe 1: Antioxidant activities of phenolic extracts and synthetic antioxidants.

\begin{tabular}{lccc}
\hline $\begin{array}{l}\text { Phenolic extract } \\
\left(30 \mu \mathrm{g} \cdot \mathrm{mL}^{-1}\right)\end{array}$ & $\begin{array}{c}\text { DPPH radical scavenging activity } \\
(\%)\end{array}$ & $\begin{array}{c}\text { Ferric reducing power } \\
(\%)\end{array}$ & $\begin{array}{c}\text { Inhibition of deoxyribose degradation } \\
(\%)\end{array}$ \\
\hline CME & $40.0 \pm 2.9^{\mathrm{c}}$ & $125.2 \pm 10.1^{\mathrm{a}}$ & $39.5 \pm 1.4^{\mathrm{a}}$ \\
SME & $31.0 \pm 4.8^{\mathrm{d}}$ & $104.3 \pm 4.5^{\mathrm{b}}$ & $42.1 \pm 2.5^{\mathrm{a}}$ \\
BHT & $30.0 \pm 1.7^{\mathrm{d}}$ & $95.9 \pm 4.5^{\mathrm{c}}$ & $32.6 \pm 2.1^{\mathrm{c}}$ \\
BHA & $52.5 \pm 8.9^{\mathrm{b}}$ & $101.2 \pm 6.0^{\mathrm{c}}$ & $36.4 \pm 1.5^{\mathrm{b}}$ \\
TBHQ & $67.1 \pm 9.1^{\mathrm{a}}$ & $107.5 \pm 13.2^{\mathrm{b}}$ & $40.2 \pm 2.0^{\mathrm{a}}$ \\
\hline
\end{tabular}

Each data point represents the mean \pm SD $(n=3)$. Different letters $(a, b, c$, and d) indicate a significant difference in columns $(p<0.05)$.

with BHT and BHA. Inhibition capacity of deoxyribose degradation of CME is not significantly different compared with that of SME and TBHQ (Table 1). Therefore, both CME and SME show potential to inhibit oxidation of fat to retard food spoilage due to their radical scavenging activity and reducing power.

Among the components of food, lipids are the quickest to deteriorate resulting in off-flavors. Egg yolk homogenate is a lipid-rich food model system for the evaluation of lipid oxidation. Egg yolk contains linoleic acid as the major polyunsaturated fatty acid. Percentage inhibitions of thiobarbituric acid reactive substance (TBARS) formation in egg yolk homogenate by CME, SME, and BHT are 71.2 \pm 2.2 , $56.8 \pm 2.7$, and $66.9 \pm 5.6$, respectively. Thus, the antioxidant activity of CME is superior to that of SME and BHT (Table 1).

Several phenolic compounds of sesame oil meal extracts prepared using different extraction methods have been identified [27]. In the present study, phenolic substances of coconut oil meal and sesame oil meal extracts were identified using HPLC techniques for comparison. Results given in Table 1 indicate that CME shows better antioxidant activities than SME in DPPH, reducing power, and deoxyribose assays at equal colorimetrically determined phenolic concentrations. As the total phenol concentrations are equal in these experiments, different antioxidant activities reflect the antioxidant capacity of the different phenolic substances present in the extracts. Most of the major phenolic substances in the extracts were identified by comparing with the retention times and UV spectra of authentic standards. Authentic standards of apigenin, caffeic acid, catechin, chlorogenic acid, cinnamic acid p-coumaric acid, daidzein, ellagic acid, epigallocatechin, ferulic acid, gallic acid, genistein, kaempferol, luteolin, naringenin, syringic acid, and vanillic acid were used for the identification phenolic compounds in CME and SME. Caffeic acid, chlorogenic acid, cinnamic acid, $p$-coumaric acid, gallic acid, kaempferl, syringic acid, vanillic acid etc., have been identified in sesame oil meal using HPLC, UV, or mass spectrometry techniques $[28,29]$. Even though the studies done on the structure and antioxidant activity relationship of plantbased phenolic compounds are meagre, there is an indication that $o$-diphenols such as hydroxytyrosol display better antioxidant activity than tyrosol which does not have $o$-diphenol functionality [30]. Presence of more than two hydroxyl substituents also supports high antioxidant activity [31]. Among identified phenolic substances, gallic acid, chlorogenic acid, caffeic acid, ellagic acid, catechin, and epigallocatechin have $o$-diphenol functionality, while gallic acid, catechin, epigallocatechin, apigenin, genistein, and naringenin have more than two hydroxyl substituents.

The thermal stability of the food preservatives is vital for the ability of those additives to increase the oxidative stability and the microbial shelf life of baked goods. Usually, cakes are baked at $160-170^{\circ} \mathrm{C}$. Therefore, $180^{\circ} \mathrm{C}$, which is at least $10^{\circ} \mathrm{C}$ higher than baking temperature, was chosen to evaluate the thermal stability of antioxidants. Thermal stabilities of phenolic antioxidants were evaluated for CME, SME, BHT, BHA, and TBHQ by heating antioxidant samples at $180^{\circ} \mathrm{C}$ for $2 \mathrm{~h}$. Then, the ability of these thermally treated antioxidants to protect phenol-stripped sunflower oil from oxidative damage was tested using the Rancimat apparatus. Rancimat curves indicating the induction time for the formation of oxidation products as measured by electric conductivity variation are given in Figure 1 . The results were compared with the results obtained for nonheated antioxidants to calculate the percent stability retained after thermal treatment. Stability parameters resulting from the Rancimat test given in Table 2 indicate that the retained stabilities of the CME and SME after heat treatment at $180^{\circ} \mathrm{C}$ for $2 \mathrm{~h}$ are 95\% and 93\%, respectively. Protection factors after heat treatment of CME and SME are $1.56 \pm 0.09$ and $1.52 \pm 0.10$, respectively, [32] have also reported protection factors ranging from 1-1.6 for several tropical fruit extracts by rancimat test at $110^{\circ} \mathrm{C}$ at comparable antioxidant concentrations.

The results indicate that the ability of antioxidant extracts and the synthetic antioxidants to protect sunflower oil against oxidation varies in the order, $\mathrm{CME}>\mathrm{SME}>\mathrm{TBHQ}>\mathrm{BHA}>\mathrm{BHT}$, while all the antioxidants provided better protection to sunflower oil compared with the control with no added antioxidants. Highest antioxidant activity of TBHQ among synthetic antioxidants is in agreement with the previously reported results [33]. CME has the highest thermal stability, while BHT has the lowest thermal stability (Table 2).

Moisture content, volume, and color are important physical parameters that affect consumer preference. Therefore, moisture content, porosity (as a measure of volume), pore area, crumb density, and cake color were analyzed for the control, BHT-added, CME-added, and SME-added cakes in order to check if added antioxidants cause any changes to the structure of cakes, thus, consumer acceptability. Among many factors including fat-to-sucrose ratio and preparation conditions of cakes, mixing intensity was the only significant factor that affects moisture content 


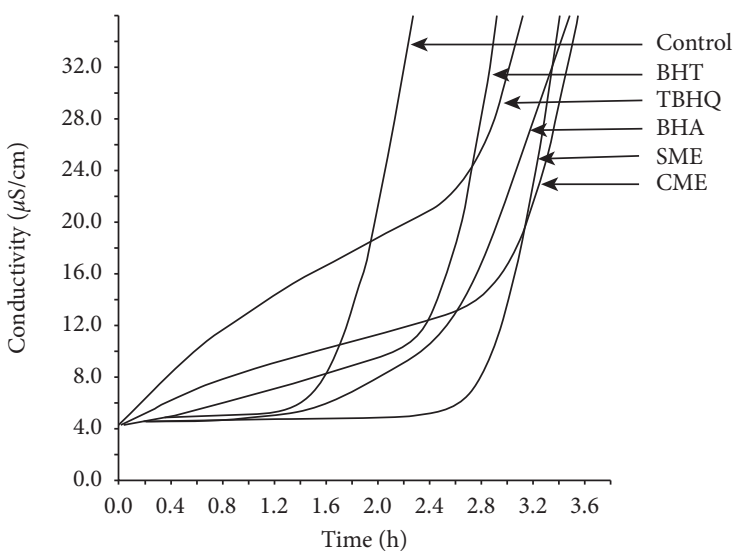

(a)

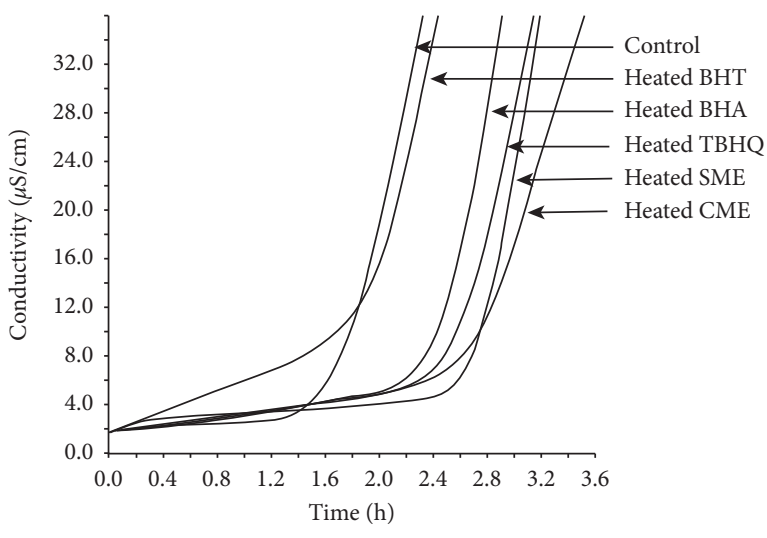

(b)

FIGURE 1: Induction time (IT) for the formation of oxidation products in sunflower oil. Variation of IT of sunflower oil with (a) antioxidants kept at room temperature and (b) heated antioxidants.

TABLE 2: Stability parameters of sunflower oil with added antioxidants $(100 \mathrm{mg} / \mathrm{kg}$ oil).

\begin{tabular}{lccc}
\hline Antioxidant in sunflower oil & Protection factor $(\mathrm{RT})$ & Protection factor $\left(180^{\circ} \mathrm{C}\right)$ & Retained stability $(\%)$ \\
\hline CME & $1.65 \pm 0.12^{\mathrm{a}}$ & $1.56 \pm 0.09^{\mathrm{a}}$ & 95 \\
SME & $1.62 \pm 0.13^{\mathrm{a}}$ & $1.52 \pm 0.10^{\mathrm{a}}$ & 93 \\
BHT & $1.32 \pm 0.10^{\mathrm{d}}$ & $1.16 \pm 0.10^{\mathrm{c}}$ & 88 \\
BHA & $1.49 \pm 0.15^{\mathrm{c}}$ & $1.39 \pm 0.14^{\mathrm{b}}$ & 93 \\
TBHQ & $1.59 \pm 0.09^{\mathrm{b}}$ & $1.45 \pm 0.04^{\mathrm{b}}$ & 91 \\
\hline
\end{tabular}

Each data point represents mean \pm SD $(n=3)$. Different letters (a, b, c, and d) indicate a significant difference within the same column $(p<0.05)$.

TABLE 3: Physical parameters of cakes.

\begin{tabular}{|c|c|c|c|c|c|}
\hline \multicolumn{3}{|c|}{$\begin{array}{ll} & \text { Control } \\
\end{array}$} & \multirow{2}{*}{$\frac{\text { BHT-added }}{20.82( \pm 1.56)^{\mathrm{a}}}$} & \multirow{2}{*}{$\begin{array}{c}\text { CME-added } \\
23.87( \pm 1.87)^{\mathrm{a}}\end{array}$} & \multirow{2}{*}{$\frac{\text { SME-added }}{23.08( \pm 0.72)^{\mathrm{a}}}$} \\
\hline Moist & & $21.83( \pm 1.12)^{\mathrm{a}}$ & & & \\
\hline Porosi & & $55.75( \pm 4.67)^{\mathrm{a}}$ & $56.96( \pm 1.14)^{\mathrm{a}}$ & $51.79( \pm 2.54)^{\mathrm{a}}$ & $54.81( \pm 0.08)^{\mathrm{a}}$ \\
\hline Crum & $\mathrm{cm}^{3}$ & $0.507( \pm 0.024)^{\mathrm{a}}$ & $0.416( \pm 0.003)^{c}$ & $0.443( \pm 0.003)^{\mathrm{b}}$ & $0.434( \pm 0.016)^{\mathrm{b}}$ \\
\hline Pore a & & $0.006( \pm 0.004)^{\mathrm{a}}$ & $0.006( \pm 0.003)^{\mathrm{a}}$ & $0.006( \pm 0.001)^{\mathrm{a}}$ & $0.006( \pm 0.001)^{\mathrm{a}}$ \\
\hline \multirow{3}{*}{ Color } & $L^{*}$ & $64.99 \pm 3.14^{\mathrm{a}}$ & $61.77 \pm 2.71^{\mathrm{a}}$ & $59.50 \pm 3.18^{\mathrm{a}}$ & $66.28 \pm 5.16^{\mathrm{a}}$ \\
\hline & $a^{*}$ & $-0.64 \pm 1.48^{\mathrm{a}}$ & $2.50 \pm 2.65^{\mathrm{a}}$ & $2.50 \pm 1.01^{\mathrm{a}}$ & $1.21 \pm 2.01^{\mathrm{a}}$ \\
\hline & $b^{*}$ & $29.02 \pm 4.88^{\mathrm{a}}$ & $31.73 \pm 4.91^{\mathrm{a}}$ & $25.13 \pm 3.50^{\mathrm{a}}$ & $31.99 \pm 6.57^{\mathrm{a}}$ \\
\hline
\end{tabular}

Each data point represents mean \pm SD $(n=3)$. Different letters $(a, b$, and $c)$ indicate a significant difference within the same row $(p<0.05)$.

[34]. Results given in Table 3 show that moisture content and the porosity of the fresh cakes are not significantly different in the cake samples containing different antioxidants compared with the control. There is a linear relationship between the porosity and the crumb density [17]. Crumb density reflects the cell size of cakes. Crumb density of antioxidant-added cakes was significantly lower $(p<0.05)$ than the control cake (Table 3 ). Increase of crumb density improves the brightness, decreases the cell size and cell wall thickness, and increase the crumb firmness in bread [35]. However, there are no reports indicating the values of crumb density that should be increased or decreased to bring about an observable change in sensory quality. Table 3 also shows that there is no significant difference among the pore areas of the cake samples, indicating that added antioxidants may not affect the pore size of cakes. Color of cakes is an important parameter that affects consumer preference. Color space components represent lightness and darkness $\left(L^{*}\right)$ varying from lightness $\left(+L^{*}\right)$ to darkness $\left(-L^{*}\right)$, difference in red and green $\left(a^{*}\right)$ varying from red $\left(+a^{*}\right)$ to green $\left(-a^{*}\right)$, and difference in yellow and blue $\left(b^{*}\right)$ varying from yellow $\left(+b^{*}\right)$ to blue $\left(-b^{*}\right)$. There is no significant difference among color space components in the control and cakes with different antioxidants. Low values close to zero are observed for $a^{*}$ in all the cakes resulting in low average values and relatively large standard deviations. Many types of cookies and cakes with colors close to yellow-brown give low $a^{*}$ values and higher $b^{*}$ values due to yellow color developed during baking. Therefore, the antioxidant-added cakes had yellow color development similar to that of the control cakes indicating that the added antioxidants do not affect the consumer acceptability due to changes in color.

Peroxide value is a useful indicator of determining the early stage of oxidation of fatty acids. The effect of antioxidants on the formation of peroxides in cake samples during storage at room temperature is given in Figure 2(a). 


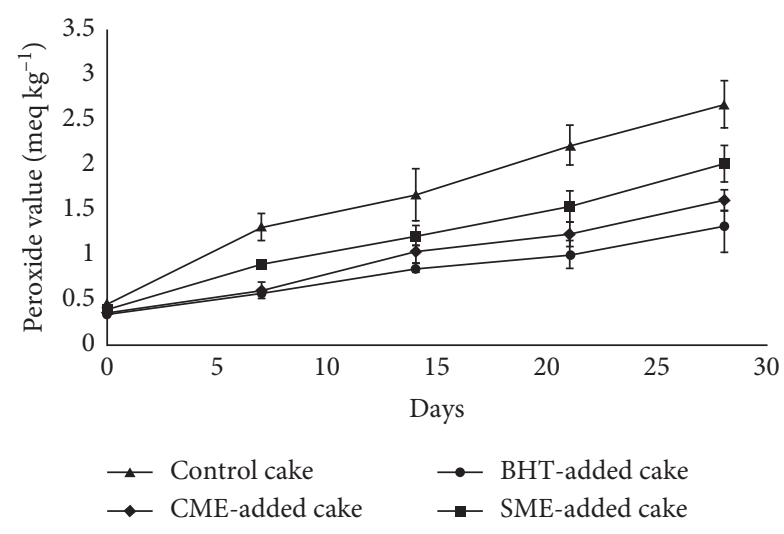

(a)

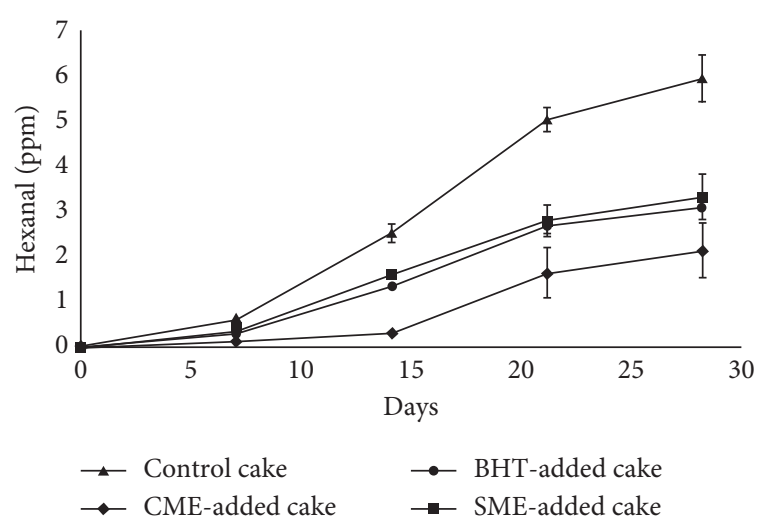

(b)

FIgURE 2: The effect of antioxidants on the formation of peroxides and hexanal in cake samples during storage at room temperature; (a) peroxide formation of cakes over time and (b) hexanal production in cakes over time. Each data point represents mean \pm SD $(n=3)$.

CME-added cake samples showed lower peroxide values than the control and other cake samples. The peroxide levels in CME-added cake samples were significantly $(p<0.05)$ lower than those in BHT-added cake samples on day 14 and day 21. Between CME and SME, CME provided higher protection against peroxide formation during storage. The effect of clove essential oil on peroxide value of cake has been reported at different concentrations. However, up to $600 \mathrm{mg} /$ $\mathrm{kg}$ concentrations of clove essential oil were required to achieve the same level of inhibition rendered by $200 \mathrm{mg} / \mathrm{kg}$ BHT in cake [36]. Most of the volatile secondary oxidation products such as hexanal, propanal, and pentane give offflavors to fat and make food less acceptable to consumers. In the present study, headspace solid phase microextraction gas chromatography (SPME-GC) was used to analyze levels of hexanal as an indicator of the formation of secondary oxidation products (Figure 2(b)). CME-added cake samples could maintain hexanal levels below $0.3 \mathrm{mg} / \mathrm{kg}$ up to at least 14 days of storage at room temperature. Longer lag time of hexanal formation indicates a higher protective effect of CME. When hexanal concentration in low-fat dehydrated foods increases above $5 \mathrm{mg} / \mathrm{kg}$, rancid odors can be observed. However, hexanal concentrations above $0.3 \mathrm{mg} / \mathrm{kg}$ affect the sensory quality [37]. Hexanal levels for day 7 at which the sensory quality of control samples may be affected due to exceeding this limit are $0.58 \pm 0.04,0.28 \pm 0.01$, $0.10 \pm 0.04$, and $0.33 \pm 0.04$ for control, BHT-added, CMEadded, and SME-added cake samples, respectively (Figure 2(b)).

Antioxidant and antimicrobial activities of phenolic compounds in baked foods is well known [6]. Microbial shelf life based on the time taken to exceed the APC $\left(1 \times 10^{5} \mathrm{CFU} /\right.$ g) and YMC $\left(1 \times 10^{3} \mathrm{CFU} / \mathrm{g}\right)$ for control cake with no added antioxidants was 7 days, while BHT-added cake samples exceeded the APC and YMC levels on day 11. CME- and SME-added cakes took 13 days to exceed the APC and YMC levels. Therefore, BHT, CME, and SME appear to have antimicrobial activity compared with the control cake samples with no added antioxidants even after exposure to high temperature during the baking process. CME and SME showed higher antimicrobial activity compared with BHT. The antimicrobial activity of the phenolic compounds present in CME and SME may contribute to the extended microbial shelf life of the antioxidant-added samples. Data of hexanal levels and microbial levels indicate that if antioxidants are not used, the quality of cakes will not be acceptable by day 7 due to microbial activity and considerable rancidity due to chemical oxidation products. Assuming that the chemical rancidity can be tolerated, the quality of cake is still not acceptable by day 7 due to high microbial levels. In agreement with the reported observations, this suggests that microbial shelf life is of higher concern than chemical rancidity for high-moisture bakery products such as cake [38]. Therefore, the extension of both microbial shelf life and chemical shelf life by BHT, CME, and SME is important for the extension of overall shelf life of cakes with respect to the control with no added antioxidants. As such, both CME and SME may serve as thermally stable natural alternatives to synthetic antioxidants for preservation of vanilla cake by extending both chemical and microbial shelf life.

Moisture content, porosity, pore area, crumb density, and color of cakes are physical parameters connected to the sensory quality. However, in addition to physical parameters, it is important to evaluate the sensory perception of cakes using a trained panel as a more practical indicator of sensory quality. Sensory evaluation was conducted within the period at which the maximum allowable microbial activity is not exceeded. Sensory characteristics of cake samples with and without added antioxidant extracts are compared in Table 4. There is no significant difference $(p<0.05)$ in the scores obtained for all the tested sensory qualities in the control and all other cake samples on day 1 . A significant decrease $(p<0.05)$ in sensory scores occurs in the control samples on day 6. Sensory scores are affected by the formation of volatile compounds. Hexanal levels above $0.3 \mathrm{mg} /$ $\mathrm{kg}$ affect sensory properties as mentioned above. High hexanal levels and high microbial counts of control compared with other cake samples may cause lower sensory scores of control on day 6. Most sensory scores for all the cake samples are significantly high $(p<0.05)$ on day 1 
TABLE 4: The sensory opinions of the panelists on control and antioxidant-added baked cake.

\begin{tabular}{|c|c|c|c|c|c|c|}
\hline & Day & Taste & Aroma & Texture & Color & Overall \\
\hline \multirow[b]{2}{*}{ Control } & 1 & $3.15 \pm 0.73^{\mathrm{ax}}$ & $2.89 \pm 0.74^{\mathrm{ax}}$ & $3.47 \pm 0.77^{\mathrm{ax}}$ & $3.84 \pm 0.37^{\mathrm{ax}}$ & $3.23 \pm 0.66^{\mathrm{ax}}$ \\
\hline & 6 & $1.38 \pm 0.51^{\mathrm{cy}}$ & $1.04 \pm 0.46^{\text {by }}$ & $1.75 \pm 0.70^{\text {by }}$ & $2.12 \pm 0.35^{\text {by }}$ & $1.50 \pm 0.53^{\text {by }}$ \\
\hline \multirow{3}{*}{ BHT } & 1 & $3.21 \pm 0.23^{\mathrm{ax}}$ & $2.84 \pm 0.89^{\mathrm{ax}}$ & $3.53 \pm 0.84^{\mathrm{ax}}$ & $3.58 \pm 0.69^{\mathrm{ax}}$ & $3.53 \pm 1.0^{\mathrm{ax}}$ \\
\hline & 6 & $2.18 \pm 0.15^{\text {by }}$ & $1.71 \pm 0.55^{\text {by }}$ & $2.50 \pm 0.65^{\text {by }}$ & $3.00 \pm 0.75^{\mathrm{ax}}$ & $2.38 \pm 0.52^{\text {by }}$ \\
\hline & 10 & $2.00 \pm 0.63^{\mathrm{ay}}$ & $1.67 \pm 0.52^{\text {by }}$ & $2.83 \pm 0.83^{\text {ay }}$ & $3.17 \pm 0.68^{\mathrm{ax}}$ & $2.23 \pm 0.58^{\mathrm{ay}}$ \\
\hline \multirow{4}{*}{ CME } & 1 & 3. $37 \pm 0.89^{\mathrm{ax}}$ & $3.26 \pm 0.87^{\mathrm{ax}}$ & $3.95 \pm 0.85^{\mathrm{ax}}$ & $3.79 \pm 0.79^{\mathrm{ax}}$ & $3.59 \pm 0.79^{\mathrm{ax}}$ \\
\hline & 6 & $2.85 \pm 0.16^{\mathrm{ay}}$ & $3.14 \pm 0.69^{\mathrm{ax}}$ & $3.71 \pm 0.49^{\mathrm{bx}}$ & $3.42 \pm 0.98^{\mathrm{ax}}$ & $3.54 \pm 0.16^{\mathrm{ax}}$ \\
\hline & 10 & $2.58 \pm 0.19^{\text {ay }}$ & $2.96 \pm 0.16^{\mathrm{ax}}$ & $2.97 \pm 0.31^{\text {ay }}$ & $3.12 \pm 0.64^{\mathrm{ax}}$ & $2.75 \pm 0.26^{\mathrm{ay}}$ \\
\hline & 12 & $2.55 \pm 0.49^{\text {ay }}$ & $2.85 \pm 0.86^{\mathrm{ax}}$ & $2.58 \pm 0.54^{\text {ay }}$ & $3.22 \pm 0.24^{\mathrm{ax}}$ & $2.70 \pm 0.56^{\text {ay }}$ \\
\hline \multirow{4}{*}{ SME } & 1 & $3.18 \pm 0.20^{\mathrm{ax}}$ & $2.63 \pm 0.57^{\mathrm{ax}}$ & $3.16 \pm 0.83^{\mathrm{ax}}$ & $3.53 \pm 0.69^{\mathrm{ax}}$ & $3.59 \pm 1.18^{\mathrm{ax}}$ \\
\hline & 6 & $2.67 \pm 0.82^{\text {ay }}$ & $2.67 \pm 0.89^{\mathrm{ax}}$ & $3.84 \pm 0.15^{\mathrm{ax}}$ & $3.68 \pm 0.82^{\mathrm{ax}}$ & $3.17 \pm 0.75^{\mathrm{ax}}$ \\
\hline & 10 & $2.34 \pm 0.24^{\mathrm{ay}}$ & $2.71 \pm 0.25^{\mathrm{ax}}$ & $3.00 \pm 0.92^{\mathrm{ax}}$ & $2.75 \pm 0.28^{\mathrm{ay}}$ & $2.75 \pm 1.04^{\mathrm{ax}}$ \\
\hline & 12 & $2.64 \pm 0.74^{\text {ay }}$ & $2.25 \pm 0.46^{\mathrm{ax}}$ & $2.66 \pm 0.36^{\mathrm{ax}}$ & $2.77 \pm 0.48^{\text {ay }}$ & $2.83 \pm 0.83^{\mathrm{ax}}$ \\
\hline
\end{tabular}

Different letters $\mathrm{a}, \mathrm{b}$, and $\mathrm{c}$ in the same column indicate significantly different $(p<0.05)$ mean consumer acceptability based on a 5-point hedonic scale $(1=$ dislike very much and $5=$ like very much $)(n=30)$ on the same day for different cakes. Different letters $x, y$, and $z$ in the same column indicates significantly different $(p<0.05)$ mean consumer acceptability for the same cake on different days.

compared with later dates. However, both CME- and SMEadded cakes retained sensory quality from day 7 to day 12 .

\section{Conclusions}

Based on the radical scavenging activity, phenolic extracts of coconut oil meal and sesame oil meal display excellent antioxidant properties. The stabilities of the phenolic antioxidants of CME and SME are not considerably lost due to thermal processing. Both CME and SME extend the microbial shelf life and oxidative stability of vanilla cake without affecting consumer acceptability. Due to favorable sensory characteristics and high thermal stability, CME and SME are ideal for extending the shelf life of baked cake and other bakery products as alternatives to synthetic antioxidants.

\section{Data Availability}

The data used to support the findings of this study are included within the article. The HPLC chromatograms, microbial counts, and the images of the cakes used to support the findings of this study are included within the supplementary information files.

\section{Conflicts of Interest}

The authors have declared no conflicts of interest for this article.

\section{Acknowledgments}

The work was supported by National Research Council, Sri Lanka (grant no. 12-012) and National Science Foundation, Sri Lanka (grant no. RG/2015/AG/03).

\section{Supplementary Materials}

Supplementary materials contain Supplementary Figure 1, Supplementary Figure 2, and Supplementary Table 1. Supplementary Figure 1 gives the HPLC chromatograms of the phenolic substances of CME and SME. Supplementary Figure 2 gives images of cakes prepared with and without antioxidants. Supplementary Table 1 gives microbial counts of control and antioxidant-added cake samples. (Supplementary Materials)

\section{References}

[1] Z. Sabouri, M. Barzegar, M. A. Sahari, and H. Naghdi Badi, "Antioxidant and Antimicrobial potential of Echinacea purpurea extract and its effect on extension of cake shelf life," Journal of Medicinal Plants, vol. 11, pp. 28-40, 2012.

[2] A. Uckiah, D. Goburdhun, and A. Ruggoo, "Vitamin C content during processing and storage of pineapple," Nutrition \& Food Science, vol. 39, no. 4, pp. 398-412, 2009.

[3] I. Izzreen and A. Noriham, "Evaluation of the antioxidant potential of some Malaysian herbal aqueous extracts as compared with synthetic antioxidants and ascorbic acid in cakes," International Food Research Journal, vol. 18, pp. 583-587, 2011.

[4] D. E. Rogers, R. B. Malouf, J. Langemeie, J. A. Gelroth, and G. S. Ranhotra, "Stability and nutrient contribution of $\beta$-carotene added to selected bakery products," Cereal Chemistry, vol. 70, no. 5, pp. 558-561, 1993.

[5] J. T. Työppönen and R. V. J. Hakkarainen, "Thermal stability of vitamin E in barley," Acta Agriculturae Scandinavica, vol. 35, no. 2, pp. 136-138, 1985.

[6] B. Nanditha and P. Prabhasankar, "Antioxidants in bakery products: a review," Critical Reviews in Food Science and Nutrition, vol. 49, no. 1, pp. 1-27, 2009.

[7] K. N. Seneviratne, C. D. Hapuarachchi, and S. Ekanayake, "Comparison of the phenolic-dependent antioxidant properties of coconut oil extracted under cold and hot conditions," Food Chemistry, vol. 114, no. 4, pp. 1444-1449, 2009.

[8] S. Ullah, A. A. Khalil, F. Shaukat, and Y. Song, "Sources, extraction and biomedical properties of polysaccharides," Foods, vol. 8, no. 8, p. 304, 2019.

[9] A. A. A. Mohdaly, I. Smetanska, M. F. Ramadan, M. A. Sarhan, and A. Mahmoud, "Antioxidant potential of sesame (Sesamum indicum) cake extract in stabilization of sunflower and soybean oils," Industrial Crops and Products, vol. 34, no. 1, pp. 952-959, 2011. 
[10] M. E. Abd-ElGhany, M. S. Ammar, and A. E. Hegazy, "Use of olive waste cake extract as a natural antioxidant for improving the stability of heated sunflower oil," World Applied Sciences Journal, vol. 11, no. 1, pp. 106-113, 2010.

[11] M. Raccach, "The antimicrobial activity of phenolic antioxidants in foods: a review," Journal of Food Safety, vol. 6, no. 3, pp. 141-170, 1984.

[12] K. N. Seneviratne, W. C. Prasadani, and B. Jayawardena, "Phenolic extracts of coconut oil cake: a potential alternative for synthetic antioxidants," Food Science and Technology, vol. 36, no. 4, pp. 591-597, 2016.

[13] K. N. Seneviratne and R. T. Kotuwegedara, "Canarium zeylanicumseed oil: an edible oil with beneficial qualities," International Journal of Food Science \& Technology, vol. 44, no. 4, pp. 792-798, 2009.

[14] K. N. Seneviratne and D. M. Sudarshana Dissanayake, "Variation of phenolic content in coconut oil extracted by two conventional methods," International Journal of Food Science \& Technology, vol. 43, no. 4, pp. 597-602, 2008.

[15] C. M. Senanayake, H. Hapugaswatte, N. Jayathilaka, and K. N. Seneviratne, "Phenolic extracts of the leaves of Psidium guineense Sw. improve the shelf life of sunflower oil and baked cake and antioxidant status of Wistar rats," Journal of Food Biochemistry, vol. 42, no. 6, Article ID e12632, 2018.

[16] M. D. Fuster, A.-M. Lampi, A. Hopia, and A. Kamal-Eldin, "Effects of $\alpha$ - and $\gamma$-tocopherols on the autooxidation of purified sunflower triacylglycerols," Lipids, vol. 33, no. 7, pp. 715-722, 1998.

[17] B. Zanoni, C. Peri, and R. Gianotti, "Determination of the thermal diffusivity of bread as a function of porosity," Journal of Food Engineering, vol. 26, no. 4, pp. 497-510, 1995.

[18] BAM, Bacteriological Analytical Manual: Department of Health and Human Services. U.S. Food and drug administration. Bacteriological Analytical Manual: 2011. Food Sampling and Preparation of Sample Homogenate, BAM, Bam, Iran, 2001.

[19] J. Wang, J.-H. Park, N.-J. Choi, S.-D. Ha, and D.-H. Oh, "Microbiological analysis of rice cake processing in Korea," Journal of Food Protection, vol. 79, no. 1, pp. 157-162, 2016.

[20] International Organization for Standards, ISO 7218-1 Microbiology of the Food and Animal Feeding Stuffs-General requirements and Guidance for Microbiological Examinations, ISO, Geneva, Switzerland, 2014.

[21] N. C. Shantha and E. A. Decker, "Rapid, sensitive, iron-based spectrophotometric methods for determination of peroxide values of food lipids," Journal of the American Oil Chemists' Society, vol. 77, no. 2, pp. 421-424, 1994.

[22] T. Waraho, V. Cardenia, Y. Nishino et al., "Antioxidant effects of mono- and diacylglycerols in non-stripped and stripped soybean oil-in-water emulsions," Food Research International, vol. 48, no. 2, pp. 353-358, 2012.

[23] K. N. Seneviratne, R. T. Kotuwegedara, and S. Ekanayake, "Serum cholesterol and triglyceride levels of rats fed with consumer selected coconut oil blends," International Food Research Journal, vol. 18, no. 4, pp. 1303-1308, 2011.

[24] S. Saha, Z. Islam, S. Islam, M. F. Hassan, M. S. Hossain, and S. M. S. Islam, "Determination of antioxidant properties and the bioactive compounds in wheat (Triticum aestivum L.)," Jordan Journal of Biological Sciences, vol. 11, no. 3, pp. 315321, 2014.

[25] J. O. Olugbami, M. A. Gbadegesin, and O. A. Odunola, "In vitro free radical scavenging and antioxidant properties of ethanol extract of Terminalia glaucescens," Pharmacognosy Research, vol. 7, no. 1, pp. 49-56, 2015.
[26] J. Treml and K. Šmejkal, "Flavonoids as potent scavengers of hydroxyl radicals," Comprehensive Reviews in Food Science and Food Safety, vol. 15, no. 4, pp. 720-738, 2016.

[27] S.-C. Lee, S.-M. Jeong, S.-Y. Kim, K. C. Nam, and D. U. Ahn, "Effect of far-infrared irradiation on the antioxidant activity of defatted sesame meal extracts," Journal of Agricultural and Food Chemistry, vol. 53, no. 5, pp. 1495-1498, 2005.

[28] R. H. Mekky, E. Abdel-Sattar, A. Segura-Carretero, and M. D. M. Contreras, "Phenolic compounds from sesame cake and antioxidant activity: a new insight for agri-food residues' significance for sustainable development," Foods, vol. 8, no. 10, p. 432, 2019.

[29] A. A. A. Mohdaly, M. F. R. Hassanien, A. Mahmoud, M. A. Sarhan, and I. Smetanska, "Phenolics extracted from potato, sugar beet, and sesame processing by-products," International Journal of Food Properties, vol. 16, no. 5, pp. 1148-1168, 2013.

[30] F. Visioli and C. Galli, "Olive oil phenols and their potential effects on human health," Journal of Agricultural and Food Chemistry, vol. 46, no. 10, pp. 4292-4296, 1998.

[31] G. Cao, E. Sofic, and R. L. Prior, "Antioxidant and prooxidant behavior of flavonoids: structure-activity relationships," Free Radical Biology and Medicine, vol. 22, no. 5, pp. 749-760, 1997.

[32] M. A. Murcia, A. M. Jiménez, and M. Martínez-tomé, "Evaluation of the antioxidant properties of mediterranean and tropical fruits compared with common food additives," Journal of Food Protection, vol. 64, no. 12, pp. 2037-2046, 2001.

[33] J. Sanhueza, S. Nieto, and A. Valenzuela, "Thermal stability of some commercial synthetic antioxidants," Journal of the American Oil Chemists' Society, vol. 77, no. 9, pp. 933-936, 2000.

[34] S. Lahtinen, M. Levola, K. Jouppila, and H. Salovaara, "Factors affecting cake firmness and cake moisture content as evaluated by response surface methodology," Cereal Chemistry Journal, vol. 75, no. 4, pp. 547-550, 1998.

[35] M. C. Zghal, M. G. Scanlon, and H. D. Sapirstein, "Prediction of bread crumb density by digital image analysis," Cereal Chemistry Journal, vol. 76, no. 5, pp. 734-742, 1999.

[36] M. I. Ibrahium, M. E. Abd El-Ghany, and M. S. Ammar, "Effect of clove essential oil as antioxidant and antimicrobial agent on cake shelf life," World Journal of Dairy \& Food Science, vol. 8, pp. 140-146, 2013.

[37] C. W. Fritsch and J. A. Gale, "Hexanal as a measure of rancidity in low fat foods," Journal of the American Oil Chemists' Society, vol. 54, no. 6, pp. 225-228, 1977.

[38] J. P. Smith, D. P. Daifas, W. El-Khoury, J. Koukoutsis, and A. El-Khoury, "Shelf life and safety concerns of bakery products-a review," Critical Reviews in Food Science and Nutrition, vol. 44, no. 1, pp. 19-55, 2004. 


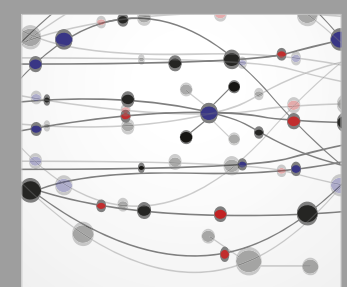

The Scientific World Journal
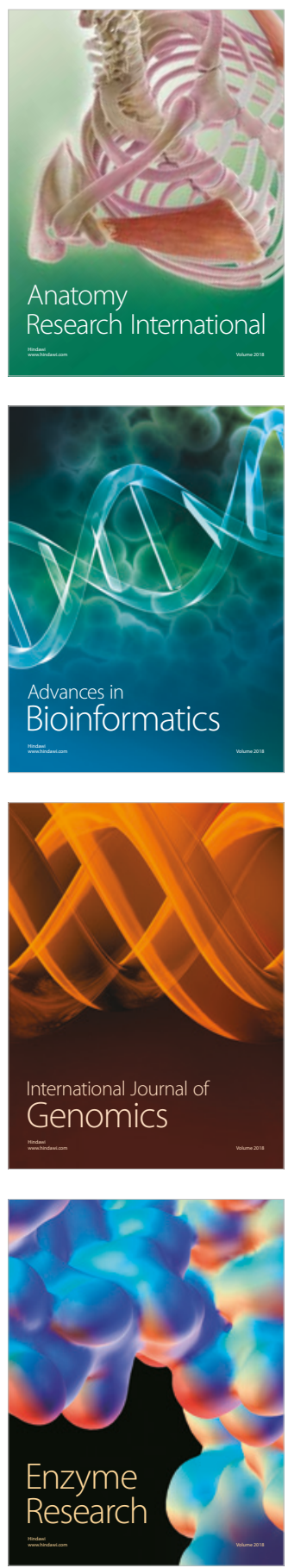
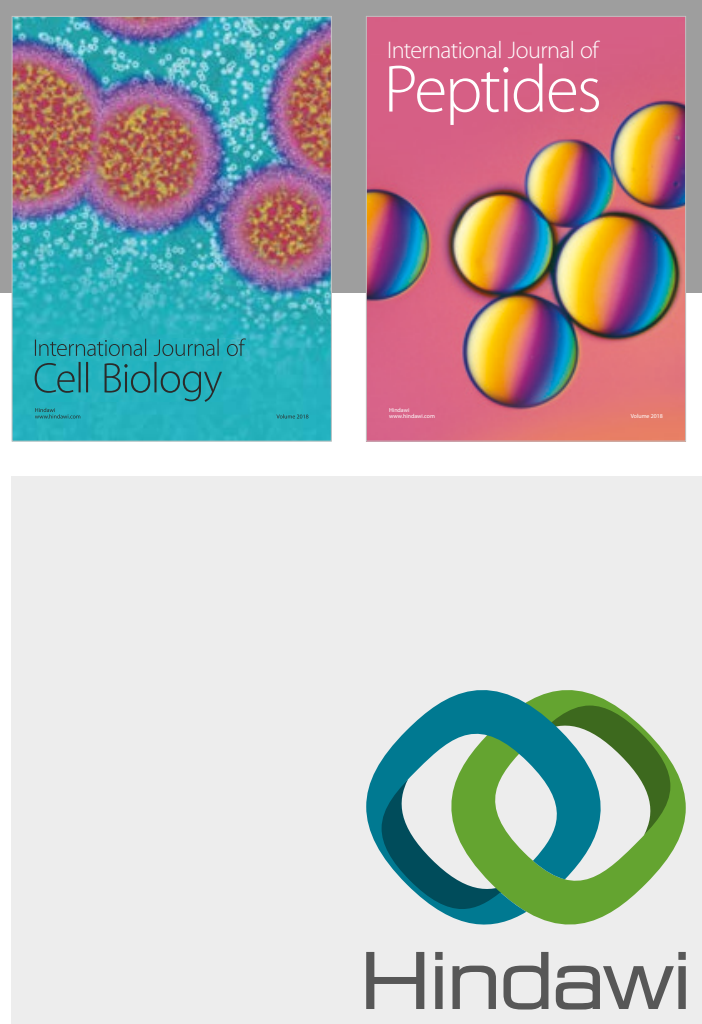

Submit your manuscripts at

www.hindawi.com
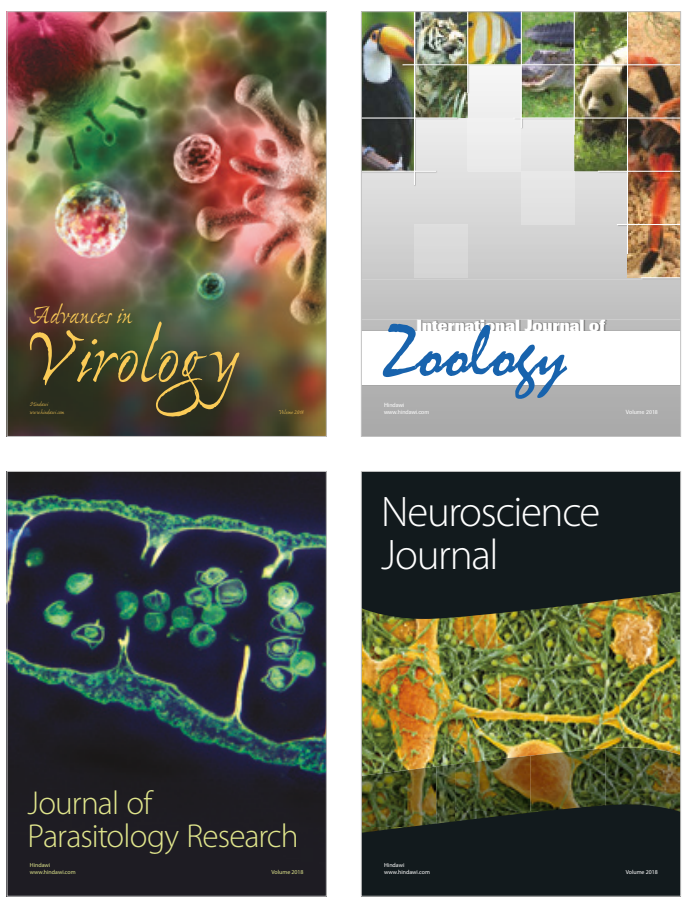
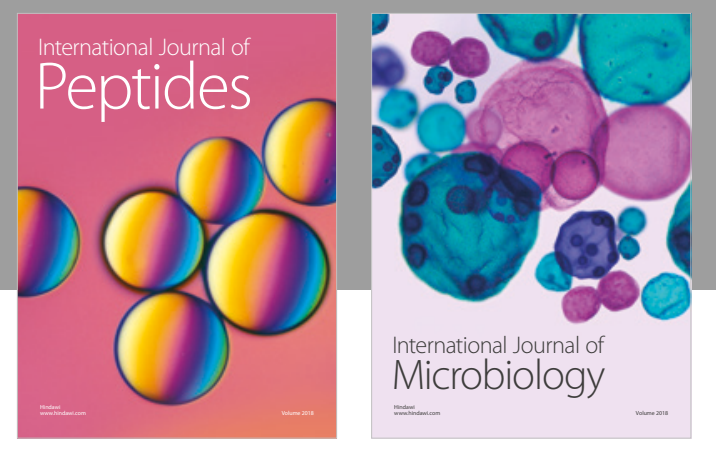

nternational Journal of Microbiology
Journal of
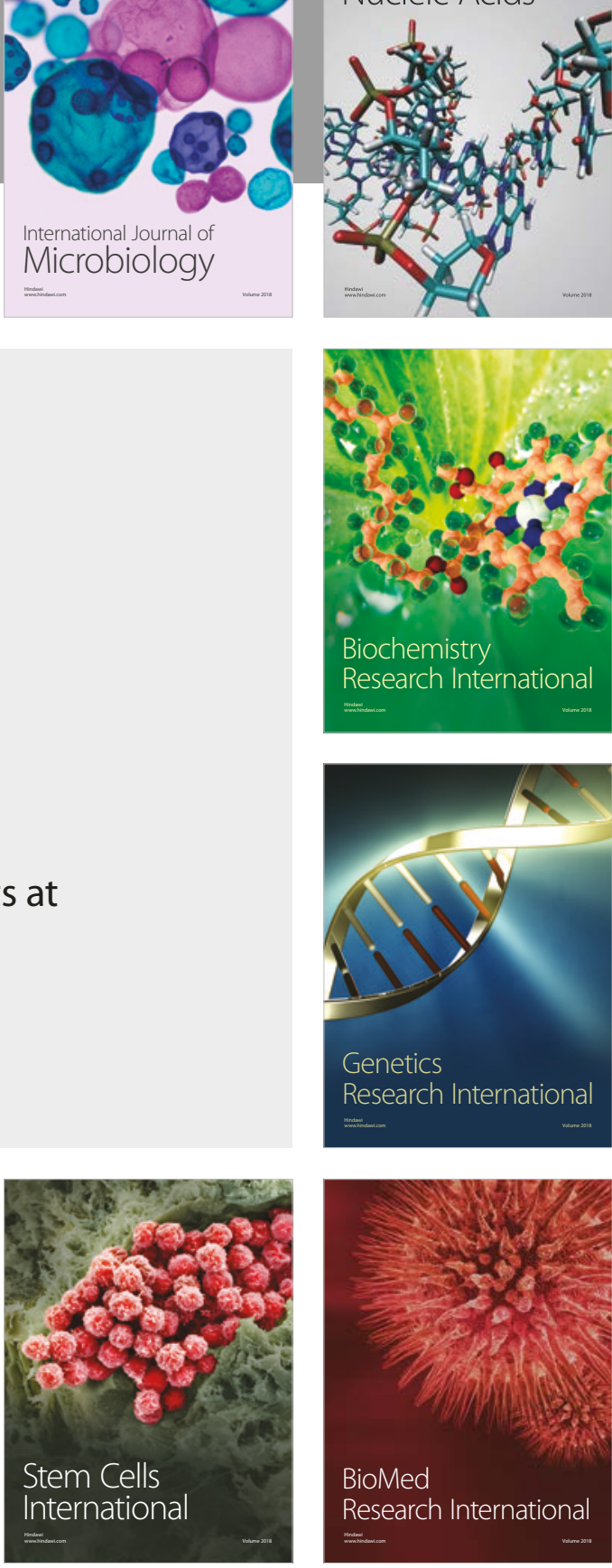
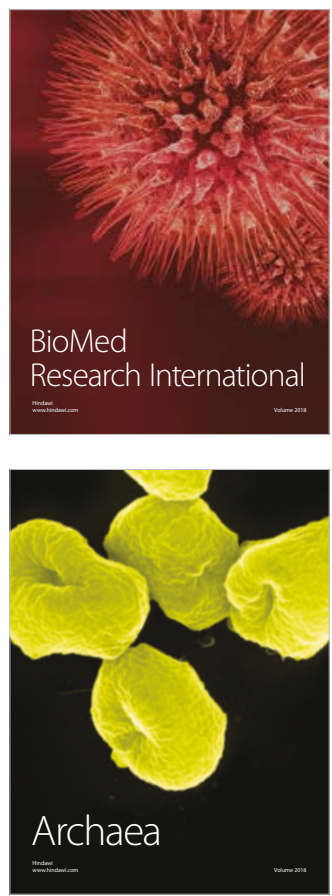